\title{
Participación en el desarrollo comunitario desde la perspectiva de las juventudes de zonas marginalizadas
}

MSc. Josseline Estefania Acuña Chacón 
Participación en el desarrollo comunitario desde la perspectiva de las juventudes de zonas marginalizadas

Participation in community
development from the perspective
of youth from marginalized areas

MSc. Josseline Estefanía Acuña Chacón Licenciada en Psicología,

Máster en Cooperación al desarrollo, con especialidad en Planificación integral del desarrollo local.

https://orcid.org/0000-0001-6724-5553

yositiffany@gmail.com

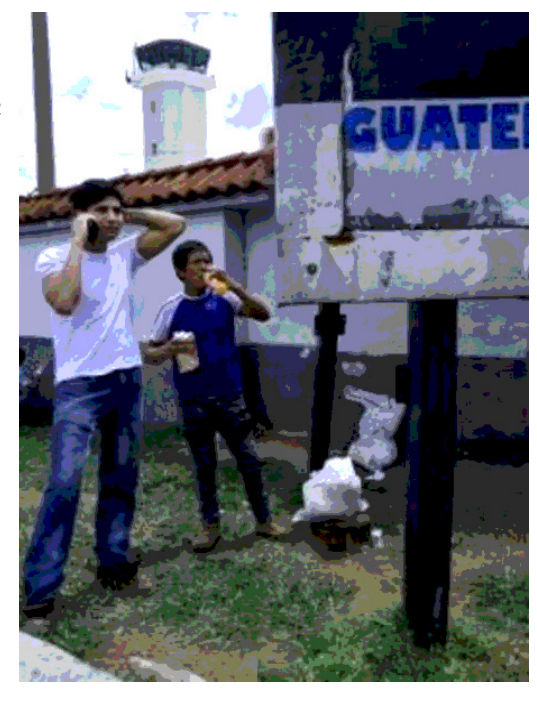

\section{PALABRAS CLAVE}

Desarrollo comunitario, participación, juventudes, experiencias vitales.

el interés era hacer audibles las voces de los participantes. De modo que, el enfoque de juventudes se constituyó en una herramienta de análisis fundamental para visibilizar las narrativas que han sido sistemáticamente silenciadas. A través del análisis de la información recopilada, se identifica que el principal significado asignado a la participación es el de proceso de transformación social, debido a que genera la posibilidad de introducir cambios positivos en su contexto inmediato, evidenciando que las juventudes aportan el desarrollo de sus entornos vitales sus conocimientos, trabajo productivo, reproductivo y comunitario.

\section{ABSTRACT}

This article is the result of qualitative research work carried out in three neighborhoods at the south of Guatemala City, with the objective of analyzing the meanings that participation in community development processes has for youth in marginalized areas, being the depth interview the main technique used in the study, because the interest was to make the voices of the participants audible. So, the youth approach became a fundamental analysis tool to make visible the narratives that have been systematically silenced. Through the analysis of the information collected, it is identified that the main meaning assigned to participation is the process of social transformation, because it generates the possibility of introducing positive changes in its immediate context, evidencing that the youth contribute to the development of their vital environments their knowledge, productive, reproductive and community work.

\section{KEYWORDS \\ community development, participation, youth, life experiences.}




\section{Introducción}

El reconocimiento de la participación activa de la población como estrategia central para el desarrollo comunitario, tiene particularidades en cada contexto, sin embargo a nivel global se ha dado especial relevancia a la participación de la juventud, porque "se estima que, aproximadamente mil millones de jóvenes entre 15 a 29 años viven en el mundo y de ellos, cerca del $85 \%$ se encuentra en países en vías de desarrollo" (Voluntarios ONU, 2016: 24), reconociéndoles como actores estratégicos y asignándoles un rol protagónico.

Este reconocimiento plantea por ende la necesidad de conocer las perspectivas específicas que poseen sobre su participación en desarrollo de sus comunidades desde sus propias vivencias y comprender cómo están participando de dichos procesos.

En estudios de juventudes se requiere de un enfoque que promueva la posibilidad de acercarse desde una perspectiva de respeto de las diferencias, porque al ser la categoría de juventud una construcción social se sabe que ser joven nunca ha significado lo mismo para todas las personas, sino que está altamente influenciado por el sector social y el territorio del que proceden, entre otros aspectos.

En el caso de las juventudes guatemaltecas, según el Informe de línea base sobre el estado situacional de los derechos de la juventud en Guatemala, la mayoría de jóvenes entre 13 y 29 años está creciendo en condiciones de pobreza en Guatemala, el 59.5\% vivía en un hogar pobre en 2014 y el $22.7 \%$ vivía en un hogar extremamente pobre (Procuraduría de los Derechos Humanos, 2019: 19) y que en las áreas urbanas de Guatemala su residencia se encuentra en zonas marginalizadas, que se caracterizan por estar localizadas en las periferias de la Ciudad de Guatemala, en una situación territorial y social conflictiva.

En este contexto, es ineludible la necesidad de comprender las perspectivas de las y los jóvenes que residen en dichas zonas, ya que son territorios en los que continuamente se promueven desde distintos agentes públicos, privados e internaciones iniciativas de desarrollo comunitario, sin embargo desde la experiencia de trabajo directo se ha evidenciado que reproducen estereotipos negativos sobre las juventudes, relacionados a su edad y situación social, que les excluye de los espacios de propuesta, liderazgo y acción relativos al desarrollo, relegándoles únicamente a necesitar intervenciones.

Por lo tanto, el objetivo de este artículo es analizar el significado que tiene para las juventudes de zonas marginalizadas del sur de la Ciudad de Guatemala la participación en los procesos de desarrollo comunitario, a partir de los aportes que identifican que realizan desde sus experiencias vitales. El estudio se delimita a tres barrios específicos, Ciudad Real, Nuevo Amanecer y La Línea, que fueron seleccionados por la interacción que existe entre ellos y sus características administrativas, asimismo porque dota a la investigación de una perspectiva territorial.

\section{Participación juvenil}

La acción de participar desde la concepción de Montero (2004) tiene al menos tres connotaciones generales:

1. Ejecutar o estar involucrado en algún acto o fenómeno social en el cual otras personas están presentes de la misma manera. 
2. Hacer partícipes a terceros de hechos o acontecimientos; informarles o de alguna manera introducirlos en alguna forma de conocimiento o de acción que emana de la fuente informadora.

\section{Compartir con otras personas ciertas circunstancias y emociones.}

Integrando las mismas se puede identificar que confluyen en la posibilidad de intercambiar y compartir tanto información como experiencias, lo cual es de importancia, porque convierte a la participación en un proceso de relación interpersonal que ocurre entre personas concretas en contextos específicos.

La participación puede tener diversos objetivos y niveles de influencia; los objetivos pueden ir desde concienciar y educar a la población, proporcionar información del barrio hasta tomar decisiones e involucrarse en la implementación de éstas; mientras que el nivel hace alusión al poder real de influir en el proceso de la política vigente.

En el contexto de estudios de juventudes tiene especial importancia la comprensión de la participación ciudadana desde la cotidianidad, debido a las características propias de la población, como lo enuncia claramente Ernesto Rodríguez: "los jóvenes se abren espacio en donde mejor se sienten, en las calles" (CLACSO TV, 2015); es decir, las y los jóvenes participan de formas menos hegemónicas, menos institucionalizadas, porque los espacios formales son en su mayoría controlados por adultos, con una visión para los jóvenes y no desde las juventudes.

La afirmación de que "los jóvenes están asentándose en el presente, presienten el futuro y encarnan los cambios más fuertes de la modernidad" (Krauskopf, 2008: 168) refleja la relevancia que tiene la participación juvenil, porque tiene el carácter dinámico que las soluciones a las problemáticas más complejas requiere, esto debido a que cuando un joven participa no sólo se involucra en el proceso de trasformación, sino que dinamiza su entorno y continúa construyendo nuevo conocimiento que facilitará una mejor comprensión de sus realidades.

Para que lo anterior sea posible es necesario facilitar espacios que permitan a la/os jóvenes actuar con autonomía, tomar decisiones y asumir la responsabilidad de las mismas, en donde la relación sea de cooperación entre generaciones, lo cual amplía las perspectivas, enriquece el espacio público y fortalece la gobernanza democrática.

En la actualidad existen espacios a nivel mundial donde este grupo etario puede dialogar y discutir en mesas técnicas, académicas y políticas que tienen incidencia en tema puntuales, así como facilitan una mejor comprensión del panorama global, regional y local siendo una conquista muy importante. Sin embargo, en el contexto latinoamericano, Guatemala sin ser la excepción, las brechas de desigualdad marcan una restricción para la mayor parte de la población joven, no de forma explícita sino debido a que se enfrentan a un contexto de carencias que restringe su posibilidad de involucrarse.

Sí se parte del postulado de que la participación ciudadana "se expresa y se practica en los territorios habituales compartidos, porque es en ellos donde a diario emerge la posibilidad de recrear sus sentidos, sus verdades y sus prácticas políticas" (Agudelo, et. al., 2013: 593), se propicia la oportunidad de ampliar las reflexiones y de analizar desde las perspectivas de las juventudes que han sido excluidas socialmente, sus propias experiencias de participar, los significados que le asignan y los aportes que realizan, para con ello tener la oportunidad de trascender la mirada que existe sobre los jóvenes de barrios marginales como grupo de riesgo hacia el enfoque de reconocerles como sujetos de derecho. 


\section{Materiales y método}

Situar el proceso de investigación con respecto a las juventudes que residen en zonas marginalizadas, tiene como punto de partida la necesidad de hacer inteligible la realidad de la población excluida en la dinámica de la sociedad actual, reconociendo que para 'investigar desde la periferia'1 se necesitan "estrategias que permitan consolidar un camino que parta de la vida ordinaria (...) y llegue a vislumbrar como horizonte la construcción del futuro, en cuyo espacio quepan todos, en donde la diferencia y la justicia sean sus premisas" (Flores, 2014: 17), es decir, generar consciencia crítica en las personas involucradas, para comprender el presente y proyectar el mundo esperado.

En ese sentido, el enfoque de investigación utilizado para este trabajo es cualitativo, porque facilita una implicación activa de los sujetos como protagonistas, produciendo conocimiento con sentido, que responde a niveles profundos de análisis, asumiendo un carácter abierto, flexible e incorpora una visión local, contextual e interconectada (Jiménez \& López, 2014). Creando así la oportunidad de conocer las peculiaridades del entorno y comprender la pluralidad de sus sentidos; todo ello sin tener la pretensión de establecer generalizaciones, sino de construir conocimiento situado que, a su vez, genere posibilidades de acción futura.

En el proceso de recolección y análisis de datos se siguió el diseño propuesto desde la teoría fundamentada en su vertiente constructiva que "considera que los seres humanos son agentes activos en la construcción de sus vidas y el mundo social en el que viven" (Jiménez \& López, 2014:115), haciendo uso de la observación participante y la entrevista a profundidad, como principal forma de acceso a fuentes primarias, se realizó un total de 8 entrevistas con jóvenes que compartieron sus experiencias de participación en sus comunidades.

Con relación al perfil de los informantes claves el grupo estuvo conformado paritariamente por mujeres y hombres, con un representante del colectivo de la diversidad sexual, que han vivido siempre en la zona y sus edades oscilan entre los 19-25 años. La totalidad de jóvenes entrevistados, están solteros, viven con familiares, y solamente una de las participantes tiene una hija.

En cuanto al nivel formativo, dos se encuentran realizando estudios universitarios, cuatro han finalizado el nivel medio, pero no han continuado estudiando, y dos poseen estudios de nivel medio inconclusos. Mientras que en lo que concierne a la situación laboral, se entrevistó a dos jóvenes que poseen empleo formal de jornada completa, una joven que trabaja en el negocio familiar con jornada extensa, tres jóvenes en situación de desempleo que se dedican a tareas de cuidado, mientras consiguen un empleo o tienen la oportunidad de seguir estudiando, y dos jóvenes que actualmente se dedican únicamente a estudiar.

\section{Resultados}

\section{Significados asignados a la participación}

La participación es entendida por las juventudes entrevistadas como el proceso de involucrarse en acciones que contribuyen a alcanzar un objetivo común que son impulsadas por algún colectivo, asignando un papel importante al sentido de pertenencia que genera formar parte del mismo, lo cual es de especial relevancia en la dinámica territorial de los barrios estudiados, porque, como plantea Montero, dicho sentido "mantiene y fortalece a la comunidad, en tanto que su ausencia genera desarticulación y destruye a la comunidad” (2004: 103). 
Las juventudes visualizan que el "estar constantemente compartiendo experiencias, compartiendo una manera de pensar y de actuar, en cierto grupo que comparte ciertos fines específicos" (IC.03)², va más allá de organizar alguna acción para llevar a cabo, y crea un sentido de vinculación con el barrio, lo cual es sumamente positivo porque siguiendo lo propuesto por Montero crea "un sentimiento de que los miembros importan los unos a los otros y al grupo, una fe compartida de que las necesidades de los miembros serán atendidas mediante su compromiso de estar juntos" (2004: 104), con lo cual se identifica que el significado está basado en una dimensión afectiva e inclusiva.

La mayoría de las juventudes entrevistadas consideran que una participación es auténtica cuando está comprometida con la transformación social, es decir que produce cambios positivos en distintos niveles, ya sea que se ayude a una persona concreta a mejorar sus condiciones de vida, se promueve acciones para solucionar alguna problemática de la comunidad o se modifique una narrativa dominante. Asimismo, evidencian que es de beneficio para las personas participantes, cuyo crecimiento personal se desarrolla positivamente y tiene un efecto político en el sentido de que forma ciudadanía.

A pesar de que los significados asignados son principalmente positivos, como colectivo poseen un sentir compartido de que en algunas ocasiones las personas se involucran para conseguir un beneficio personal, que va desde el reconocimiento social hasta conseguir algún bien, es decir, que existe un significado egoísta por parte del sujeto participante, lo cual en cierta medida se ve reforzado debido a la existencia de espacios que promueven procesos con un sentido únicamente utilitarista, en los cuales se espera que la población genere inputs sobre la propuesta presentada.

Las juventudes entrevistadas plantean que se debe promover que los procesos participativos comunitarios respondan a intereses colectivos porque, a pesar de que esto no implica que no existan conflictos de diversas índoles, ya que en un barrio siempre existirán diferentes actores con múltiples intereses, plantean que existe mayor probabilidad de que más personas se involucren y confíen en los procesos cuando se atiende a un sentir compartido.

Los procesos de participación son vistos de forma muy diversa por las/os jóvenes, no se constriñen a ningún espacio institucionalizado, sino son percibidos como contextos de mayor apertura, pero en cierta medida difusos, esto en parte se debe a que en el territorio no se han impulsado procesos de participación pública, sino únicamente han existido iniciativas de grupo pequeños.

Reconocen también que como jóvenes tienen diversas áreas de interés, pero que no por ello se debe reducir su participación sólo a aquellos temas que se piensa que son probablemente los que más les atraen, sino que se les debe permitir estar presentes en todos los ámbitos, como lo plantea uno de los participantes:

Como jóvenes podés participar en todas las temáticas porque somos seres integrales y no podemos desatender una para pensar en otra, pasa por ejemplo con las iniciativas de leyes que surgen en Guatemala, especificamente la $5272^{3}$, eso es un ejemplo de cómo se reduce la participación del joven, y sólo nos involucran en el deporte o el arte, a pesar que también podemos abordar otros campos, en los que podemos aportar al menos sistematizando experiencias, para que las personas que se encargan de ejecutar y hacer las propuestas sepan lo que en serio se necesita, entonces podemos hablar de educación, de política, de cultura, de trabajo, de diversidad, en todos los elementos creo, porque al final de cuentas somos un ciudadano más, como cualquier otro" (IC.04).

\footnotetext{
${ }^{2}$ IC - Informante clave
}

${ }^{3}$ Iniciativa de ley 5272 para la Protección de la Vida y la Familia, plantea el incremento de las penas de cárcel para mujeres que decidan interrumpir su embarazo voluntariamente, la prohibición expresa del matrimonio entre personas del mismo sexo y de la difusión de cualquier información acerca de la diversidad sexual y de género en las escuelas y centros de formación, además de censurar la discusión de otras formas de sexualidad distintas a la heterosexual. 
Esta reflexión refleja la necesidad de que existan espacios de diálogo inclusivos con las autoridades, en los cuales las juventudes se sientan verdaderamente escuchadas, ya que en la actualidad los pocos espacios existentes son de limitado acceso.

\section{Aportes de las juventudes a los procesos de desarrollo comunitario}

Tras dialogar con las juventudes, se ha podido documentar los principales aportes que consideran que realizan al desarrollo de sus familias y comunidades. El análisis se lleva a cabo tomando como punto de partida sus experiencias de vida, por lo cual se presentan breves relatos que permiten dimensionar y comprender el impacto que dichas acciones tiene en sus realidades.

Las juventudes aportan saberes y conocimientos: La generación de jóvenes que viven en zonas marginales en la actualidad, ha tenido un mayor acceso a la educación con respecto a sus padres, por lo cual tienen la posibilidad de contribuir en su entorno aportando los conocimientos que han adquirido en la escuela y otros saberes que han ido construyendo en diferentes contextos.

Creo que he aportado a mi familia que he podido estudiar un poco más entonces, por ejemplo, los puedo ayudar con la tecnología, porque ahora que es una gran ayuda, yo puedo utilizar la computadora y puedo ayudarlos con eso, es un acceso más, un avance" (IC.05).

Esto implica que no sólo ellos pueden tener acceso a otros contextos, sino mejora la realidad familiar porque las nuevas habilidades que adquieren contribuyen, por ejemplo, a reducir las brechas digitales existentes, facilitando de esta forma el acceso a nueva información, o también acercan a la comunidad otros servicios educativos a los que de otra forma no tendrían acceso.

"Pienso que aporto la parte de orientación académica, ayudo a mis hermanos con sus estudios para que seamos más en la familia los que tengamos esa posibilidad de terminar nuestros estudios, pienso que con lo que he aprendido he ido aportando, ayudando a mi mamá para que comprenda mejor algunas cosas y a mi papá con aspectos de historia que le gustan (...). En mi comunidad, sigo atendiendo niños que tienen alguna dificultad de aprendizaje o discapacidad, aportando asi a una mejor calidad de vida para ellos, esto lo hago con precios accesibles, es más algo simbólico, para que valoren el servicio" (IC.04).

Paulo Freire (2007) plantea que alfabetizar es sinónimo de concienciar, por lo cual se puede constatar que las juventudes están actuando como verdaderos facilitadores del conocimiento en sus comunidades, porque por medio de procesos de diálogo cercano generan en sus familiares, amigos y vecinos la posibilidad de comprender de forma distinta su realidad.

Por lo anterior es de suma importancia que se aseguren praxis educativas liberadoras, que permitan al individuo tomar conciencia, que incentiven la creatividad y criticidad de las juventudes, para que de esta forman puedan desarrollar sus propias iniciativas más allá del espacio del aula, como ha sido emprendido por las/os participantes de la investigación.

Las juventudes trabajan y dinamizan la economía local: Las juventudes inician aportar a la economía familiar desde temprana edad, por medio de trabajos medio tiempo, apoyando en los negocios familiares o contribuyendo con parte de sus ingresos mensuales que devienen de un empleo formal. 
"Yo soy comerciante, le ayudo a mis padres a administrar su negocio, tienen varios puestos en el mercado, uno de plásticos, uno de cocina y otro de lentes (...) trabajo todos los días de 7 de la mañana a 8 de la noche y sólo un día a la semana tengo descanso, los martes, de ahi seguido todos los días (...). Yo miro directamente un negocio, yo les digo que yo voy a ver cómo hago para atraer a la gente, mientras mi papá se dedica a administrar el negocio y mi mamá va a comprar mercadería" (IC.03).

"La situación económica en mi casa es bastante dura porque sólo mi mamá era la que trabajaba, mi papá nos ayudaba de vez en cuando, no entiendo cómo le hacía mi mamá para estirar tanto el dinero, porque ella trabaja en un comercio informal, nos daba desayuno, almuerzo, cena, pasajes, con $Q .40^{4}$ el día (...) por eso tomé la decisión de trabajar y no seguir la universidad este año, ha sido bueno porque ya ayudo en la casa y ya no miro tanta presión sobre mi mamá, me siento un poco más tranquilo", (IC.07).

Debido a que reconocen las limitantes económicas que han tenido a lo largo de su vida, saben que es de importancia el aporte que puedan realizar, porque de esta forma dan mayor estabilidad a sus familias y contribuyen a garantizar el acceso a recursos básicos de subsistencia, sin embargo, en pocos casos evidencian que no están siendo garantizados sus derechos labores, limitando el ejercicio de otros derechos inherentes a su condición de jóvenes.

Lo anterior es producto de las tendencias en los mercados laborales en América Latina, en donde ha disminuido la importancia del empleo formal y con ello la seguridad social, así como la organización sindical; se han ampliado las relaciones salariales precarias, sin contrato ni garantías, ha crecido el desempleo abierto, ha aumentado la migración como mecanismo de ajuste y se expande el autoempleo de subsistencia (AVANCSO et. al., 2013: 228). Es decir, se consolida un modelo basado en la máxima explotación y esquema de relaciones labores flexibles, lo cual tiene impacto directo en la juventud, debido a que el trabajo como asunto público ha centrado su discurso en la cuestión juvenil.

Las juventudes realizan trabajo del hogar y de cuidados: Según los datos presentados en el ENJU, se estima que las juventudes guatemaltecas invierten el $17.4 \%$ de horas semanales al trabajo familiar no remunerado. Mientras que al trabajo doméstico y cuidado de personas un promedio de $23 \%$ no obstante, al observar los datos desagregados por sexo en esta categoría, se observa que el $45.9 \%$ de las mujeres invierten más de 20 horas a la semana, mientras que el $34 \%$ de los hombres únicamente de 1 a 10 horas y, un 39.5\% expresa no realizar tareas domésticas frente a un $12.1 \%$ de mujeres (Instituto Nacional de Estadística et. al., 2011, pp. 178-180).

En conjunto ambas actividades representan el $40 \%$ del tiempo total semanal que, como se evidenció, puede variar en función de las otras actividades a las que él o la joven se dedique en el resto del tiempo, que está influenciado por las brechas sociales del país, especialmente por la desigualdad de género.

Ayudo en los quehaceres de la casa y ayudo a mis hermanas cuando salen, a cuidar a las niñas" (IC.01). 
Estoy estudiando para entrar a la universidad y ayudando en mi casa (...), yo ahora de lunes a viernes me quedo en la casa y asumo todas responsabilidades de la casa, limpieza, cocinar, ir a traer a mi sobrina a la escuela, pero yo quiero tener una oportunidad también para trabajar en lo que he estudiado (...) creo que uno de los aportes que hago en mi familia es ser un ejemplo para mis sobrinas, creo que es algo pequeño pero importante, porque con 18 años soy la única que estudia de mis hermanas y que no tengo hijos, entonces creo que les doy un ejemplo de seguir adelante" (IC.02).

El trabajo del hogar y de los cuidados, llamado trabajo doméstico, continúa estando completamente invisibilizado, las juventudes que lo realizan en su mayoría forman parte en las estadísticas de los llamados NINIS (ni estudia, ni trabaja), sin tomarse en cuenta el trabajo no remunerado que realizan en sus hogares, tampoco se considera como dichas labores perpetúan las brechas de desigualdad de género y limitan la oportunidad de acceder a un trabajo remunerado y/o de continuar estudiando.

Es indispensable que se reconozca el impacto socioeconómico que tiene el trabajo del hogar y los cuidados, así como que se visibilice el rol que están teniendo las juventudes en la denominada economía del cuidado.

Las juventudes realizan voluntariado: El voluntariado tiene diferentes significados y formas de ser entendido, de acuerdo al contexto dependerá de múltiples factores. En los presentes relatos, es considerado como una estrategia que les han permitido a las/os jóvenes conocer personas, ampliar sus redes y lograr colectividad.

Estuve en un grupo de voluntariado para atender a personas con discapacidad y fue una experiencia interesante porque se ve que hay un estigma con las personas vulnerabilizadas, entonces me gustaba participar en esa parte de sensibilización, pero también ayudaba en cosas más concretas" (IC.04).

Soy de los miembros fundadores de un movimiento juvenil llamado ZOOM, es genial la verdad, porque ayudamos por los motivos correctos, sabemos que todos podemos y debemos hacer algo que ayude a las demás personas, como el simple hecho de limpiar espacios comunes, pintar un mural o hacer actividades que nos recuerden la importancia de no perder nuestra sensibilidad humana, ZOOM es como un abrir la mente, concientizarse, darse cuenta que hay muchas cosas que hacer por el mundo, y que aunque yo no pueda resolver las problemáticas del país, al menos soy sensible a la realidad y las injusticias sociales" (IC.07).

Una de las características compartidas por las juventudes entrevistadas es que han participado de acciones de voluntariado, para el beneficio de la comunidad o de algún colectivo en situación de vulnerabilidad, percibiéndose su disposición al servicio comunitario, que visualizan como un canal de transformación tanto a nivel personal, porque como jóvenes voluntarios se sensibilizan de distintas problemáticas, como a nivel social, porque muestran que el esfuerzo conjunto de la población permite lograr objetivos comunes que de otra forma no se conseguirían, así como estimular la creación de un mayor capital social.

Lo anterior cobra especial relevancia, porque como juventudes están apostando a la creación y/o recuperación del tejido social de sus comunidades, que ha sido debilitado por la incursión de las pandillas y estructuras del crimen organizado en el territorio, por este motivo consideran que es relevante continuar promoviendo actividades de este tipo en sus comunidades para que más jóvenes se interesen e involucren, porque en la actualidad, es escasa la movilización juvenil. 
Además, la labor voluntaria de las juventudes entrevistadas puede ser entendida como un proceso de contra estigmatización, porque permite iniciar a visibilizar a las/os jóvenes como individuos que se preocupan por la realidad y tienen el deseo de transformarla, siendo una respuesta directa al enfoque de criminalización o al de rehabilitación-prevención que ha imperado. Por ello se evidencia la necesidad de dar mayor soporte desde el Estado, la cooperación internacional y otros actores privados, a las iniciativas comunitarias lideradas por jóvenes, lo que requiere una adecuación de sus mecanismos de acción, para que se ajusten a las lógicas de funcionamiento local y juvenil.

\section{Resultados y discusión}

La participación es para las juventudes entrevistadas, la acción de involucrarse en algo para lograr un objetivo común y cuando esta adquiere los adjetivos de social y/o ciudadana, la meta compartida hace alusión a la construcción de un mejor país (comunidad, mundo) para todas y para cada uno, porque la diversidad y la justicia son sus premisas.

Algunos de los significados asignados a la participación están relacionados a la creación de relaciones interpersonales, debido a que esta genera sentido de pertenencia y facilita vínculos afectivos en los espacios comunitarios, lo cual es de especial relevancia porque posiciona la importancia de la promoción de espacios de participación como un medio para lograr ciertos objetivos concretos y permitir el encuentro entre la población entorno a problemáticas comunes.

El significado primordial asignado a la participación por las juventudes entrevistadas es el de la transformación, porque cuando el proceso es genuino, provoca cambios positivos. Esta valoración está influenciada por sus experiencias personales de participación que en su mayoría han estado vinculadas a acciones de voluntariado.

Los distintos aspectos analizados, permiten confrontar el discurso hegemónico, que considerado a las juventudes que residen en zonas marginalizadas como objeto de control e intervención debido a que viven en entornos de violencia; con la realidad de que son actores que aportan a los procesos de desarrollo de sus comunidades, porque desempeñan roles productivos, reproductivos y comunitarios.

A raíz del conocimiento y análisis de las realidades de los barrios estudiados, se evidencia la importancia y urgencia de promover procesos de desarrollo comunitario verdaderamente planeados, incluyentes e integrales, en los cuales, además de asegurar que todas las personas sean tomadas en cuenta, se garantice la atención y respeto de sus diferencias.. 


\section{Referencias bibliográficas}

Agudelo Ramírez, A., Murillo Saá, L., Echeverry Restrepo, L., \& Patiño López, J. (2013). Participación ciudadana y prácticas políticas de jóvenes en la cotidianidad. Revista Latinoamericana de Ciencias Sociales, Niñez y Juventud, 11(2), 587-602.

Asamblea General de las Naciones Unidas. (1986). Declaración sobre el derecho al desarrollo.

Asociación para el Avance de las Ciencias Sociales (AVANCSO) e Instituto de Estudios Humanisticos de la Universidad Rafael Landívar (Coords). (2013). Jóvenes en Guatemala: Imágenes, discursos y contextos. Ciudad de Guatemala.

Botero Gómez, P. (2008). Perspectivas teóricas para comprender la categoría de participación ciudadana. Revista Latinoamericana de Ciencias Sociales, Niñez y Juventud, 6(2), 565-611.

CLACSO TV (23 de julio de 2015). Perspectivas: Entrevista a Ernesto Rodriguez [archivo de video]. Recuperado de: https://youtube.com/watch?v=R6mWPCtQZn.

Flores Osorio, J. M. (2014). Investigar desde la periferia. En J. Flores, \& J. Aparicio (coords.), Miradas y prácticas de la investigación psicológica y social (págs. 15-44). Puebla: Benemérita Universidad Autónoma de Puebla.

Fondo de Población de las Naciones Unidas. (2009). El enfoque de juventudes: hacia una visibilización positiva de las personas jóvenes. Costa Rica.

Freire, P. (2007). La educación como práctica de la libertad. Madrid: Siglo XXI Ediciones.

Instituto Nacional de Estadística, et. al. (2011). Primera encuesta nacional de juventud en Guatemal (ENJU). Guatemala.

Jiménez, B., \& López, R. (2014). Psicología social crítica e investigación cualitativa: una relación necesaria. En J. Flores, \& J. Aparicio, Miradas y prácticas de la investigación psicológica y social (págs. 79-127). Puebla: Bemérita Universidad Autónoma de Puebla.

Krauskopf, D. (2008). Dimensiones de la participación en las juventudes contemporáneas latinoamericanas. (A. E. Carolina, Ed.) Pensamiento Iberoamericano(3), 165-184. 
Montero, M. (2004). Introducción a la psicología comunitaria: Desarrollo conceptos y procesos. Buenos Aires: Editorial Paidós.

Procuraduría de los Derechos Humanos. (2019). Informe de línea base sobre el estado situacional de los derechos de la juventud en Guatemala. Guatemala.

Rebollo, O. (2003). Bases político-metodológicas para la participacíón. Ciudades para un futuro más sostenible(24).

Rebollo, O. (2011). Desigualdad, participación y democracia. Nuevos retos de la participación e impactos en la vida. Enguera: Seminaris d'estiu Enguera.

Voluntarios ONU. (2016). Jóvenes por los ODS. Programa de Voluntarios de la Naciones Unidas. 